\title{
Reuse of Technical Manufacturing Processes in the Space Area
}

\author{
Amauri Silva Costa ${ }^{1} \star$, Leonel Fernando Perondi ${ }^{1}$ José Eduardo May
}

Costa AS (DiD https: / /orcid.org/0000-0001-8734-9106

How to cite

Perondi LF (10) https: / / orcid.org/0000-0002-0165-7018

Costa A S; Perondi L F; May J E (2020) Reuse of technical manufacturing processes in the space area. J Aerosp Technol Manag, v12: e4720. https://doi.org/10.5028/ jatm.v12.1184

ABSTRACT: The article explores the reuse of technical processes in the manufacturing of space systems, from the perspective of establishing a database of technical manufacturing processes for use by space organizations. It will be argued that the reuse of processes is made feasible when a database of processes is implemented and that the reuse of technical manufacturing processes provides gains in time, cost, and reliability. A proposal for the organization of project technical processes into a database is presented. The article addresses the following topics: technical process concepts, control and use of technical manufacturing processes practiced by space agencies, identification of technical manufacturing processes, and their organization in a database. Finally, an example of the application of reuse is presented, and the main consequences of the reuse of technical manufacturing processes with the aid of a database are discussed.

KEYWORDS: Technical processes; Space technology; Manufacturing; Fabrication; Qualification.

\section{INTRODUCTION}

The reuse of qualified processes among different projects and missions, while not new in the space area, does not seem to have a well-established standard among space agencies hitherto. The information regarding qualified technical processes are of great importance for current and future projects in an organization. Driven by the view that the reuse of technical processes provides gains in reliability, time and cost, this paper presents a proposal for the implementation of a database of space qualified technical processes for use inside an organization, or even among space organizations.

In the space area, to ensure the reliability of the flight model of an equipment or system, verification models, specific for each phase of the development of the equipment or system, are used. The main such models are the engineering model, conceived for the verification of the functional conformity of the design proposed for the considered item, and the qualification model, conceived for the verification of the functional and environmental conformance of the design and manufacturing of the considered item (ECSS 2009).

Once demonstrated the conformity of the engineering and qualification models, the flight model is manufactured, which must be equivalent, functionally and constructively, to the qualification model. To accomplish this planning, it is necessary, among other actions, to control manufacturing processes, whose reproducibility is essential to ensure the constructive and functional reproducibility of the flight model, as alluded above. It should be noted that manufacturing activities formally begin with the fabrication of process tools, followed by the manufacturing and integration of the qualification model. Reproducibility will only be achieved if the manufacturing processes themselves are reproducible. The concept of a qualified process is thus introduced to designate processes whose reproducibility has been demonstrated (ECSS 2009, 2018).

The qualification of a technical manufacturing process mostly consists of demonstrating that the process meets all relevant requirements and that it can be reproduced from a general description. In general, such description comprises the definition of the input parts and materials, a detailed description of the environment, the step-by-step procedure for the execution of the process, and a detailed description of the setup setting, including tooling and instructions for operator training (ECSS 2009, 2018).

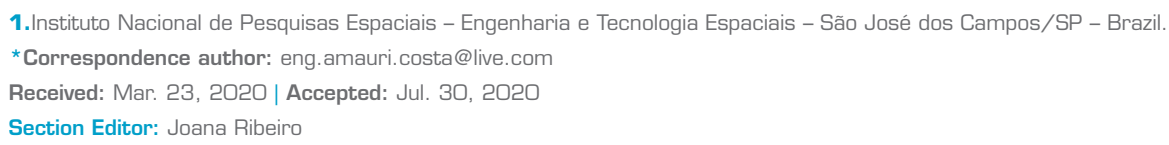


During the execution of a project, process control is exercised to ensure that processes used in the project are qualified. Upon completion of a project, information regarding qualified technical processes may be relevant for future programs, to the extent that such processes may be reused, with or without changes in other missions, providing time and cost savings, as well as improved reliability.

Technical processes must be described, identified, and classified in a standard way, as well as organized in a database in order to be reused in the ambit of different programs and projects. The importance of reusing technical manufacturing processes is illustrated in this paper, in an example in which technical processes developed for the China-Brazil Earth Resources Satellite (CBERS) program, specifically for the CBERS-3\&4 satellites, have been reused in the AMAZONIA-1 satellite program, evidencing economies of scale stemming from the adoption of qualified processes of one program by another program, in the same organization.

The paper begins discussing the concept of technical processes and their control and use in space organizations, as well as introducing the concept of a technical process database. After that, the organization of such databases and their application in the reusing of technical processes are addressed. In the sequence, the positive consequences of process reusing among different projects and programs are discussed, emphasizing benefits due to improved efficiency and reliability. Finally, the conclusions of this research are given.

\section{TECHNICAL PROCESSES}

Definitions and general requirements for technical manufacturing processes are given in the standard NASA-STD-6016A, Standard Materials and Process Requirements for Spacecrafts (NASA 2016).

According to this document, changes in material and processes shall be documented in the material identification and usage list (MIUL) during the execution of a project. In each project, all processes used by the hardware developer must be submitted to prior approval by the agency. The documentation approach is defined in the plan for selecting, controlling, and implementing materials and processes.

The Materials and Processes Technical Information System (MAPTIS) database is a NASA's quality system initiative that provides an accessible computerized interface for users. The MAPTIS database provides information on materials and processes, which have been previously approved, identified, and documented in the MIUL (NASA 2016).

European Space Agency (ESA) projects make use of information consolidated in the European Cooperation for Space Standardization (ECSS) standards (ECSS 2019a). In particular, technical manufacturing processes are approached according to the standard ECSS-Q-ST-70C, Space Product Assurance - Material, Mechanical parts, and Processes (ECSS 2019b).

According to this standard, every project should implement a process control initiative, which must ensure that all processes used in the manufacturing of the qualification and flight models are documented in detail, with well-defined criteria of rejection and acceptance (ECSS 2019b).

In general, process control aims at ensuring that every process used for manufacturing the qualification and the flight models has been documented, with modifications always updated, guaranteeing that such processes are repetitive and that their use generates products that meet project requirements (ECSS 2019b).

According to the ECSS (2019b), every supplier of a program/project should present a declared process list (DPL) with all the processes necessary to manufacture the item under its responsibility. This list should be updated at each phase of the project.

Every process is subjected to a criticality analysis, aimed at classifying processes according to the following definition: every process that is either new to a company, has not been previously verified for the current application, or has displayed a not yet solved non-conformity in a previous application is defined as a critical process (ECSS 2019b).

Every critical process must be identified in the DPL and submitted to customer approval upon a request for approval (RFA). The supplier must implement for each critical process a verification plan according to previously defined internal standards. For processes that do not conform to project requirements, the supplier must submit a deviation request (waiver), at the end of either the criticality analysis or the verification tests, according to previously defined internal procedures. Processes that are defined as noncritical do not require approval requests. However, these processes should also be controlled (ECSS 2019b).

At the Instituto Nacional de Pesquisas Espaciais (INPE), some processes qualified and successfully used in CBERS missions were reused in the Amazonia-1 mission, given its similarity of application, contemporaneity, manufacturing controls, and training 


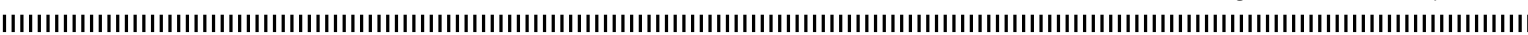

of operators. Examples of reuse of process are the processes associated with the forming and welding of electronic components, the manufacturing of printed circuit boards, and the application of thermal resins and their fixation.

With the implementation of a database, process information from the execution of many projects can be made available to other missions, providing time and cost savings, and gains in reliability. The setting up of a database, in its turn, requires the establishment of a classification and identification scheme.

The following sections present proposals for the identification and classification of processes aimed at their organization in a process database.

\section{DESCRIPTION, IDENTIFICATION AND CLASSIFICATION OF TECHNICAL MANUFACTURING PROCESSES}

The reuse of technical manufacturing processes requires maintaining up-to-date and detailed information about these processes, possibly from multiple developers (ECSS 2019b). The number of such processes in a project is extensive, with each process requiring a great deal of information data for its implementation and reproduction. Putting into action a strategy to reuse the process requires the organization of this vast amount of information in a way that it can be easily checked and retrieved, for instance, as in a digital database. An example of digital database is the one already cited from NASA.

To organize technical processes in such a database for reuse, it is essential that the processes get a standardized description and identification (NASA 2016). The identification, among other elements, shall include a classification based on the primary type of processing implemented by the process, thus giving a specific identity to each process. Such classification might, as well, facilitate inspection and control work, by quality assurance personnel, for instance.

\section{STANDARD DESCRIPTION OF A PROCESS}

Following the International Council on Systems Engineering (INCOSE 2015), it is proposed that processes be described by an IDEF0-type diagram, with the elements shown in Fig. 1.

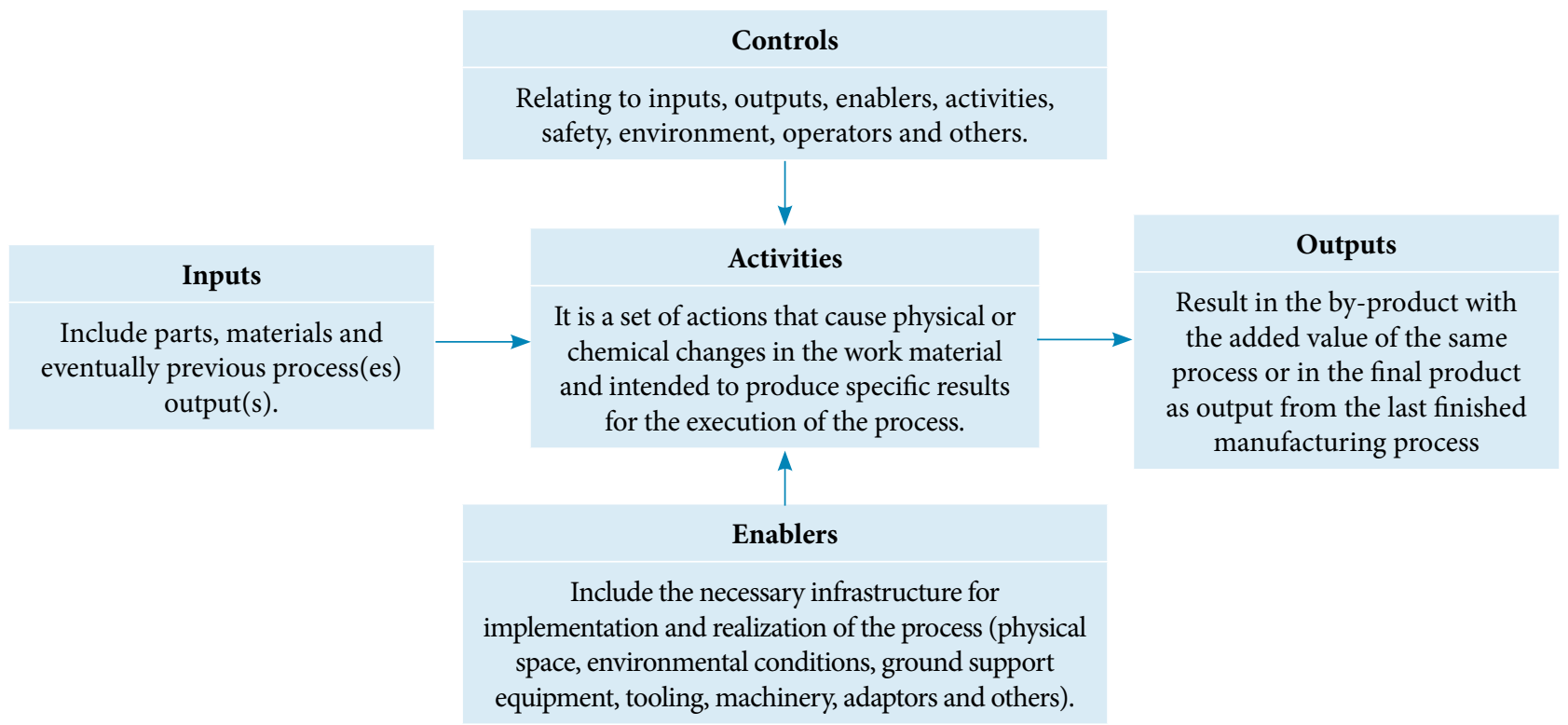

Figure 1. Elements and description of a technical manufacturing process. Adapted from INCOSE (2015) and Groover (2019). 
The elements of a process are defined as inputs, outputs, controls, enablers, and activities. The proposed definitions for such elements are as follows (INCOSE 2015; GROOVER 2019):

- Inputs: Include parts, materials and eventual previous processes' outputs; the parts and materials of the inputs differ from the parts and materials of the enabler elements because they are physically added to the work material and remain aggregated to the product even after its completion;

- Outputs: are composed by the by-product(s) of the process, with the added value from the process; by-product(s) of the process may have the form of other materials, energy or information derived from the process;

- Controls: are requirements applicable to inputs, outputs, enablers, activities, safety, environment, operators and others; such requirements may be related to regulations and laws, standards, procedures, agreements, guidelines, and project control actions;

- Enablers: include the necessary infrastructure for implementation and realization of the process (physical space, environmental conditions, ground support equipment, tooling, machinery, adaptors, and others);

- Activities: are the detailed set of actions that cause physical or chemical changes in the inputs to produce specific results from the implementation of the process.

Essentially, it is proposed that all qualified processes, used in projects, programs, and missions, and which will be stored in the database, get a description according to the elements above defined.

\section{CLASSIFICATION OF TECHNICAL MANUFACTURING PROCESSES}

Technical manufacturing processes can be classified according to the type of the primary processing operation carried out over the work material. Table 1 presents a framework for the classification of manufacturing processes, originally proposed by Groover (2019), which seeks to classify technical manufacturing processes according to the type of transformation that occurs in the work material.

Table 1. Proposal for the classification of technical manufacturing processes according to the type of transformation of the work material.

\begin{tabular}{|c|c|c|c|}
\hline \multirow{12}{*}{$\begin{array}{c}\text { Technical } \\
\text { manufacturing } \\
\text { processes }\end{array}$} & \multirow{7}{*}{ Processing operations } & \multirow{4}{*}{ Shaping } & Solidification \\
\hline & & & Particulate \\
\hline & & & Deformation \\
\hline & & & Material removal \\
\hline & & Property enhancing & Heat treatment \\
\hline & & \multirow{2}{*}{ Surface processing } & Cleaning and surface treatment \\
\hline & & & Coating and deposition \\
\hline & \multirow{5}{*}{ Assembly operations } & \multirow{3}{*}{ Permanent joining } & Welding \\
\hline & & & Brazing and soldering \\
\hline & & & Adhesive bonding \\
\hline & & \multirow{2}{*}{ Mechanical fastening } & Threaded fasteners \\
\hline & & & Permanent fastening \\
\hline
\end{tabular}


Additional levels of classification may be aggregated to the framework of Table 1. For each process, classified according to the type of transformation, as described in the last column of Table 1, there may exist variations in its execution, with changes in one or more of its elements (inputs, activities, outputs, controls, and enablers). Managing such variations in a database may be difficult due to the large number of variation possibilities. It is proposed that this difficulty be overcome by the introduction of "blank" fields, which would be tailored to specific needs associated with the description of a given concerned process.

\section{IDENTIFICATION OF TECHNICAL MANUFACTURING PROCESSES}

In order to set up a process database, processes must be uniquely identified. Next, a proposal for the content of the alphanumeric string, i.e., the primary key, which uniquely identifies a given process in the database, is discussed.

As usual in the design of databases, the primary key is composed of a combination of attributes, which, besides uniquely identifying a given record, conveys useful information about the record, speeding up the retrieval of information from the database.

In the given context, it is proposed, based on the authors' experience, that the primary key should contain, among other attributes, the identification of the institutional owner of the process, the classification of the process, as already discussed above, and the qualification status of the process. Figure 2 shows the complete proposal for the primary key of the processes in the database, where (a1) Process developer (XXXX); (a2) classification level of the information (X): O - open; R - reserved; S - secret; T - top secret; (b) technical classification according to the type of transformation of the work material; (c) sequential number attributed to the version of the process implementation; $(\mathrm{d})$ status $(\mathrm{X})$ gives the current approval status of the process (A - approved; X approved with RFA; W - approved with concession; $\mathrm{O}$ - open; R - rejected) and existence of alerts (n) regarding the process ( 0 - without alerts; 1 - the process has one or more alerts); (e) number of projects in which the process has been used; (f) other: an open field for future assignment.

$\overbrace{\mathrm{X} X \mathrm{X} X}^{\mathrm{a} 1}-\overbrace{\mathrm{X}}^{\mathrm{a} 2}-\overbrace{\mathrm{n} \mathrm{n} n}^{\mathrm{b}}-\overbrace{\mathrm{n} n}^{\mathrm{c}}-\overbrace{\mathrm{Xn}}^{\mathrm{d}}-\overbrace{\mathrm{n} n}^{\mathrm{e}}-\overbrace{\mathrm{n} n}^{\mathrm{f}}$

Figure 2. Proposal for the identification of technical manufacturing processes.

Next, a detailed description of each element of the proposed primary key is presented.

\section{a1 - Identification of the process developer}

Each technical manufacturing process used in an organization is developed either in-house or by an external provider. Given that the information relative to a given process may display competitive value for organizations and, typically, is subjected to intellectual property rights, it is fundamental that the identification of each documented technical process clearly displays the identification of the organization responsible for its development.

\section{a2 - Classification level of the information}

The information associated with the process may display different levels of secrecy due to the commercial or competitive value of its intrinsic elements. It is proposed that each process be classified according to the degrees of secrecy given in Table 2 .

Table 2. Classification level of information.

\begin{tabular}{|c|c|}
\hline Code & Description \\
\hline $\mathrm{O}$ & Open, when your content is considered public and/or there is no access restriction. \\
\hline $\mathrm{R}$ & Reserved, when your content requires restricted access for 5 years. \\
\hline $\mathrm{S}$ & Secret, when your content requires restricted access for 15 years. \\
\hline $\mathrm{T}$ & Top secret, when your content requires restricted access for 25 years. \\
\hline
\end{tabular}




\section{$b-$ Technical classification of the process}

The technical classification of the process has been given in Table 1 .

\section{$c$ - Sequential number}

The sequential number of the process gives the version of process implementation. For each process, there may exist variations in its execution, with changes in one or more of its elements. Process version identifies changes in the inputs, activities, outputs, controls, and enablers elements.

\section{d-Qualification status and alerts}

The qualification status of a process is proposed to follow the ECSS standard according to the adaptation shown in Table 3.

Table 3. Process qualification status control.

\begin{tabular}{|c|c|}
\hline Code & Description \\
\hline A & $\begin{array}{l}\text { Approved. } \\
\text { The process has proven qualification and can be used without restrictions. }\end{array}$ \\
\hline $\mathrm{X}$ & $\begin{array}{l}\text { Approved with Request for Approval (RFA). } \\
\text { The process was submitted to the evaluation and verification program and approved. It can be used } \\
\text { without restrictions. }\end{array}$ \\
\hline $\mathrm{W}$ & $\begin{array}{l}\text { Approved with concession. } \\
\text { Even though the process did not meet all the requirements of the project, it was used for special reasons. } \\
\text { As a guideline, its reuse should be reduced to the maximum extent possible. }\end{array}$ \\
\hline $\mathrm{O}$ & $\begin{array}{l}\text { Open. } \\
\text { Although displaying an approved or not approved status from previous projects, the process currently has a } \\
\text { verification report or a deviation request (waiver) under customer's evaluation. } \\
\text { Another possibility is that the process has relevant investigations and evaluations in progress. }\end{array}$ \\
\hline $\mathrm{R}$ & $\begin{array}{l}\text { Rejected. } \\
\text { The process has not yet been approved for use in any previous project. The process has a status of rejected } \\
\text { because it has not met requirements or because it displays insufficient technological maturity to be used in } \\
\text { a project. } \\
{ }^{\star} \text { It is recommended that the process has its information stored in the database, in such a way that it may be } \\
\text { used in a future project with compatible requirements, or that the continuity of its development bring its } \\
\text { status to an acceptable level of maturity. }\end{array}$ \\
\hline
\end{tabular}

Adapted from ECSS (2019b).

According to the ECSS, an alert is a "formal notification to users, informing them of failures or nonconformance" (ECSS 2012). It is proposed that relevant alerts associated with the process are communicated through the control pattern shown in Table 4. The alert information for each process must be declared in the database.

Table 4. Process alert control.

\begin{tabular}{c|c|}
\hline Code & Description \\
\hline 0 & No alert records. \\
\hline i & The process does not have alert records. \\
\hline & Has one or more alerts. \\
\hline
\end{tabular}




\section{$e-N u m b e r$ of uses}

Each use of the process should be informed, describing the program, project, and product in which the process was used. It is proposed that a numerical identifier be assigned to each use of the same process in different projects.

\section{$f$ - Other}

There may be other attributes that show themselves as peculiar and relevant information, that do not fit in any of the characteristics so far considered in this proposal of a primary key. In order to accommodate such situations, an empty field is proposed.

Figure 3 presents a possible example of the identification of a given process in the proposed database, where (a1) process developer (INPE); (a2) classification level of the information (O); (b) technical classification of coating and deposition (132), according to the classifications given on Table 1; (c) sequential number attributed to the version of the coating and deposition process - 6061 aluminum surface paint with INK MAP PU1 (01); (d) approved without restrictions status (A) and has no record of alerts (0); (e) the number of projects in which the process has been in use; the process displays a count of two (2) uses in its usage history; (f) open field for future assignment.

$\overbrace{\text { I P E E }}^{\mathrm{a} 1}-\overbrace{\mathrm{O}}^{\mathrm{a} 2}-\overbrace{132}^{\mathrm{b}}-\overbrace{01}^{\mathrm{c}}-\overbrace{\mathrm{A} 0}^{\mathrm{d}}-\overbrace{02}^{\mathrm{e}}-\overbrace{0 \quad 0}^{\mathrm{f}}$

Figure 3. Example of identifying technical manufacturing processes of coating and deposition.

\section{REUSE OF PROCESSES}

Making use of the description, classification, and identification of technical processes given above, the setting up of a process database is proposed, enabling, among other possibilities, the reuse of technical manufacturing processes across missions and programs.

For each new mission, the database is updated with all the qualified processes used in the mission, displaying, for each process, information such as revision dates, history of use and alerts, intellectual property, as well as any other relevant information.

\section{REASONS FOR THE REUSE OF TECHNICAL MANUFACTURING PROCESSES}

The reuse of manufacturing technical processes developed for one mission by future missions, partially or in full, provides time and cost savings, as well as gains in reliability.

According to a report by INPE's Process, Materials and Mechanical Parts Group (INPE 2015), the AMAZONIA-1 project has made extensive use of technical manufacturing processes developed for the CBERS-3\&4 satellite program.

Table 5 presents, as an example, an excerpt from the list of the technical processes qualified for the CBERS-3\&4 program reused in the AMAZONIA-1 program.

The processes from the CBERS-3\&4 program listed in Table 5 and reused in the AMAZONIA-1 program gave clear gains to the latter, in terms of cost, time, and reliability, illustrating the main point of this paper, that the adoption of qualified processes in a program by another program of the same organization is of great advantage for the organization.

Deploying process reuse in an organization requires careful consideration as regards selection and requirements. Typically, during the Phase $\mathrm{C}$ of a project, when developing the as-designed data package for the product's equipment, the manufacturing processes to be used in the manufacturing of each equipment are selected.

The selection of processes must guarantee the reliability, inspectability, and susceptibility of each process' outputs. It should also guarantee the reproducibility of each process (ECSS 2019b). 
Table 5. Examples of technical manufacturing processes qualified for the CBERS- $3 \& 4$ program. Processes numbered 1 to 8 have been reused in the AMAZONIA-1 program.

\section{Qualified Processes for the CBERS3\&4 Program}

1 - Alodine Application Process on Aluminum Surfaces

2 - Cv-2946 Resin Preparation and Application Process

3 - EC2216 Adhesive Preparation and Use Process

4 - SMT Component Welding Process

5 - Process for Pre-forming Flat-Pack Components in the Fancort Machine

6 - Process for Welding SMA Connectors on Semi-Rigid Coaxial Cables

7 - Microwave Absorber Bonding Process

8 - Interfiller Application Process

9 - CV-2500 Silicone Preparation and Use Process

10 - Epoxy Preparation and Use Process STYCAST 2850FT Black

11 - Epoxy Preparation and Use Process EPO-TEK 930

12 - Preparation and Use Process RTV566

13 - PCB Component Cleaning Process

14 - Map-PU ink marking and identification process

15 - Z-306 ink painting process

16 - Heat treatment process stress relief of aluminum alloy parts 6061

Adapted from INPE [2015].

According to the ECSS (2019b), processes should be chosen from those already checked, according to the following order of preference and priority:

- Processes considered as best practices by space agencies or other governmental certification organizations, for equivalent conditions of use;

- Processes for which satisfactory evaluation and verification results have been obtained, in representative samples of the application, with enough safety margin in relation to the conditions of use; and

- Processes already used by the same supplier for other space programs, under the same conditions of use.

It is worth noting that the reuse of processes does not intend to eliminate the need for new developments in manufacturing techniques but to be part of the continuous improvement cycle ordinarily present in every organization.

\section{POSITIVE CONSEQUENCES STEMMING FROM THE REUSE OF TECHNICAL MANUFACTURING PROCESSES WITH THE AID OF A DATABASE}

Among the main positive consequences derived from the reuse of processes, with the aid of a database, the following are singled out:

- There is the possibility that it will not be necessary to submit all processes in the perspective of use, in a given project, to a qualification program, considering that many of these processes may already have been used in the past, in other projects, and thus display a qualified process status; from the process database, one can search for processes already used in past projects, the use of which fits with the needs and conditions of use associated with the current project;

- The reuse of processes, typically, provides a reduction in the amount of material and human resources in the development of a system; as a consequence, there will also be a reduction of cost and time in product development; 
- The reuse of processes in a new project, provided that equivalent conditions of use are maintained, is equivalent to reducing the project risk, since it guarantees that the reliability already achieved in previous project's products, a reliability level which has been verified in flight hardware, will be kept for the products of this new project. The database is essential in keeping track of the history of use of each process;

- As other application of the database, it ought to be mentioned that its use will allow, eventually, the licensing of processes among processes' owners, enabling eventual commercial exchanges and associations among developers of space products; and

- Finally, the database allows for an improvement in elements such as reliability, cost, and time.

As a final example of the application of a database of technical processes, mention ought to be made to the possible use of such a database in the selection of equipment providers, aimed at mitigating the risk associated with industrial contracts.

After the establishment of a sufficiently large and varied process database, which is taken as a reference for a given organization, it is possible, in principle, to establish a measure of how far a list of processes presented by a given provider departs from the reference defined by the processes already present in the database: the higher the departure, the larger the risk associated with the contract of the given provider.

By making use of this approach, an organization might improve the effectiveness of its bidding procedures, by allocating, in a substantiated way, a risk to each possible bidder, thus allowing an improved decision making in purchases (GONDO 2012).

\section{CARE IN THE REUSE OF PROCESSES}

In space projects, the product's conformance to the requirements and specifications is verified to a great extent (ECSS 2019a). It would, thus, be expected that the reuse of a process could be carried out without additional tests related to the concerned process. Best practices, however, require that each reuse of a process be preceded by careful tests and analysis, which shall demonstrate the suitability of the process to the new intended use.

A policy that favors the reuse of given processes should not be taken as a reason to postpone or avoid investments in related research and development of new manufacturing techniques, which would, eventually, abolish the use of the concerned processes. In short, the adoption of a policy of process reuse in an organization should not represent a driver that favors obsolescence of manufacturing processes and techniques in the organization.

Process reuse requires the maintenance of a database to manage and maintain updated information from several developers. For instance, according to the ECSS standard, it is recommended that all internal processes be reviewed every four years. At INPE, the technical manufacturing processes in use are reviewed every two years.

The reuse of processes, on the one hand, promotes the reduction of the volume of material and human resources used in the development of systems, promoting, consequently, the reduction of cost and time of development of the product. On the other hand, the reuse of processes requires greater rigor in the control of the documentation associated with the technical information accumulated from projects.

\section{CONCLUSION}

This paper addressed the reuse of technical manufacturing processes, in projects and programs of agencies and organizations, from the standpoint of the implementation of a database of manufacturing processes.

The reuse of technical manufacturing processes provides gains in time, cost, and reliability. Processes subjected to reuse may undergo simplified qualification procedures, or even be exempted from such qualification procedures, depending on the application.

In industrial arrangements with many companies, it is, in principle, possible to get even higher cost and time savings with the licensing or sharing of technical manufacturing processes among companies. 
The exposition in the paper has been tailored to convey the idea that the reuse of processes in the scope of space projects is thoroughly feasible when a database of processes is implemented, and critical information about qualified processes is systematically recorded.

The reuse of processes requires some care due to the possibility of a slowing down of necessary developments in new manufacturing techniques. The setting up of a process database enables the recording of the history of use of processes, from which an alert system might be implemented.

As additional positive consequences stemming from the setting up of a process database, it ought to be mentioned the possible licensing of processes among processes' owners, enabling eventual commercial exchanges among developers of space products, as well as the use of technical processes, by an organization, as a way of improving the effectiveness of its bidding procedures.

\section{ACKNOWLEDGMENTS}

Editors and authors are thankful to Fundação Conrado Wessel for providing the financial support for publishing this article.

\section{FUNDING}

There are no funders to report for this submission.

\section{AUTHOR'S CONTRIBUTION}

Conceptualization: Costa A. S., Perondi L. F. and May J. E.; Methodology: Costa A. S., Perondi L. F. and May J. E.; Investigation: Costa A. S., Perondi L. F. and May J. E.; Writing - Original Draft: Costa A. S., Perondi L. F. and May J. E.; Writing - Review and Editing: Costa A. S., Perondi L. F. and May J. E.; Supervision: Costa A. S., Perondi L. F. and May J. E.

\section{REFERENCES}

[ECSS] European Cooperation for Space Standardization (2009) Space engineering: System engineering general requirements. ESA Requirements and Standards Division. ESTEC; Noordwijk, Netherlands. [accessed Feb 26 2020]. http://ecss.nl/get_attachment. php?file=standards/ecss-e/ECSS-E-ST-10C6March2009.pdf

[ECSS] European Cooperation for Space Standardization (2012) ECSS system: Glossary of terms. Noordwijk: ESA Requirements and Standards Division. [accessed Feb 26 2020]. https://ecss.nl/standard/ecss-s-st-O0-01 c-draft-1-1-glossary-of-terms-13-january-2012/

[ECSS] European Cooperation for Space Standardization (2018) Space product assurance: Quality assurance. ESA Requirements and Standards Division. ESTEC; Noordwijk, Netherlands. [accessed Feb 26 2020]. https://ecss.nl/standard/ecss-q-st-2Oc-rev-2-qualityassurance-1-february-2018/

[ECSS] European Cooperation for Space Standardization (2019a) Document tree (ECSS architecture). [accessed Nov 12 2019]. https:// ecss.nl/standards/ecss-document-tree-and-status/

[ECSS] European Cooperation for Space Standardization (2019b) Space Product Assurance: Material, mechanical parts and processes. Paper presented ESA Requirements and Standards Division. ESTEC; Noordwijk, Netherlands. [accessed Feb 26 2020]. https://ecss. nl/ standard/ecss-q-st-70c-rev-2-materials-mechanical-parts-and-processes-15-october-2019/

[INCOSE] International Council on Systems Engineering (2015) INCOSE Systems Engineering Handbook: A guide for system life cycle processes and activities. Hoboken: John Wiley \& Sons.

[INPE] Instituto Nacional de Pesquisas Espaciais (2015) Minutes of Meeting A823300-MOM-02237 - Process, Materials and Mechanical Parts Group - INPE. São José dos Campos: INPE. [accessed Feb 26 2020]. 
[NASA] National Aeronautics and Space Administration (2016) Standard materials and processes requirements for spacecraft. NASASTD-6016A. Washington: NASA. [accessed Feb 26 2020]. https://standards.nasa.gov/sites/default/files/standards/NASA/DRAFT/ Baseline/NASA-STD-6016A.pdf

Brazil. Lei $n^{0}$ 12.527, de 18 de novembro de 2011. Regulamenta o direito constitucional de acesso dos cidadãos às informações públicas. Diário Oficial da União 18 nov. 2011. [accessed Feb 26 2020] http://www.planalto.gov.br/ccivil_03/_ato2011-2014/2011/ lei/I12527.htm

Gondo SMH (2012) Proposta de metodologia para o tratamento de processos na fabricação de plataformas orbitais no âmbito do programa espacial brasileiro (Thesis). São José dos Campos: Instituto Nacional de Pesquisas Espaciais. In Portuguese.

Groover MP (2019) Fundamental of modern manufacturing, materials, processes and systems. Hoboken: John Wiley \& Sons. 